\title{
IMPROVING PERFORMANCE OF SME'S USING SUPPLY CHAIN FRAMEWORK AND MULTI-CRITERIA DECISION METHODOLOGY
}

\author{
Madani Alomar \\ Industrial and Manufacturing Systems Engineering \\ University of Windsor \\ Windsor, ON, Canada \\ E-mail: alomarm@uwindsor.ca \\ Zbigniew J. Pasek \\ Industrial and Manufacturing Systems Engineering \\ University of Windsor \\ Windsor, ON, Canada \\ E-mail: zjpasek@uwindsor.ca
}

\begin{abstract}
This paper proposes a model that will assist enterprises, in particular small and mediumsized manufacturing enterprises (SMEs), assess their supply chain performance by prioritizing supply chain strategic attributes and processes and selecting an adequate strategy under various market demand scenarios. The outlined model utilizes and integrates the SCOR framework standard performance attributes and processes and AHP approach to construct, link, and assess a four level hierarchal structure. The model also may help SMEs in deciding how much emphasis to place on supply chain operations and management.
\end{abstract}

Keywords: performance measurement system, AHP, supply chain processes, supply chain attributes, performance improvement, SME, expert choice.

\section{Introduction}

Manufacturers today are facing global challenges such as low cost rivals, fluctuating products and services prices, increasing customer expectations, and unstable economic conditions. The ambiguity associated with these issues has added on one hand significant changes in the business environment resulting in tremendous growth and opportunities for new markets, and on the other hand in increased frequency and complexity of challenges that threaten the operations and survival of firms. These competitive pressures are motivating manufacturing firms to continuously reconsider and adjust their competitive strategies, supply chains, and manufacturing technologies in order to improve performance, compete, and survive long- term. Small and medium-sized enterprises (SMEs) are much more exposed to these external pressures than larger firms, thus their reactions often fall short, due to limited resources and capabilities (e.g., financial resources, managerial talent, and access to markets). 
This paper proposes a procedural approach based on a decision-support model that will assist SMEs in building a strategic and flexible performance measurement system that considers supply chain performance attributes based on Supply Chain Operations Reference (SCOR) framework, supply chin attributes and processes, and various market demand scenarios.

\section{Literature Review}

Various studies have revealed that small businesses are extremely susceptible to failures; about $50 \%$ of small businesses in Canada and 53\% in the United States fail to survive for more than five years (Branch, 2012). Several research studies have linked the success of businesses to the type of performance measurement system (PMS) used by the firms and to the successful design and implementation. Other researchers have considered strategic performance measurement system as a means to achieve competitive advantage, continuous improvement and ability to successfully manage changes (Cocca and Alberti, 2009). Despite these results, several investigators found that many small enterprises predominantly emphasis financial index only (Gosselin, 2005), neglecting the others. Moreover, a study (Arend and Winsner, 2005) revealed that there is a poor fit between supply chain management and the small and medium-sized enterprises. The authors attributed this poor fit to variety of reasons such as improper implementation of supply chain management by the small and medium-sized enterprises, and due to the lack of use of supply chain management to complement strategic focus. The proposed model fills the gap by constructing a performance improvement model that includes supply chain performance attributes and processes based on a well-known framework.

\section{Hypotheses/Objectives}

Unlike other previous works where the use of AHP and performance measures were mainly addressing the selection of best supplier, vendors, markets or manufacturing departments, this work suggests an improvement model that links enterprise performance under different market circumstances to supply chain performance measures and processes. The objective of the study is to show and demonstrate that we can customize and implement well-known supply chain frameworks, initially designed for large firms, in smaller enterprises by employing adequate procedure that helps in organizing and ranking criteria in a simple structure.

\section{Research Design/Methodology}

Because each and every business encounters different market demands, three different market scenarios in level 1 of the model were employed. The second level consists the five supply chain performance attributes that involve both financial and non-financial aspects. The third level presents the major supply chain processes, which can be found almost in every business. The selection of the attributes and processes are based on wellknown framework, the SCOR framework that mainly used by larger firms. The model was implemented on a family owned medium-sized enterprise using AHP and expert choice software. The levels judgments conducted by the assistant general manager of the 
enterprise who did the judgments based on the business preferences and with aid from the authors of this paper.

\section{Data/Model Analysis}

The structure of the model is shown in figure 1. The hierarchy of levels starts with level 0 or the goal and ends with supply chain processes. Figure 2 and 3 show screen shots of the first level pairwise and the second level comparison taken from the model using Expert Choice software. Figure 4 is the overall ranking of supply chain processes with respect to the goal. Figure 5 shows the local and global values of levels one and two.

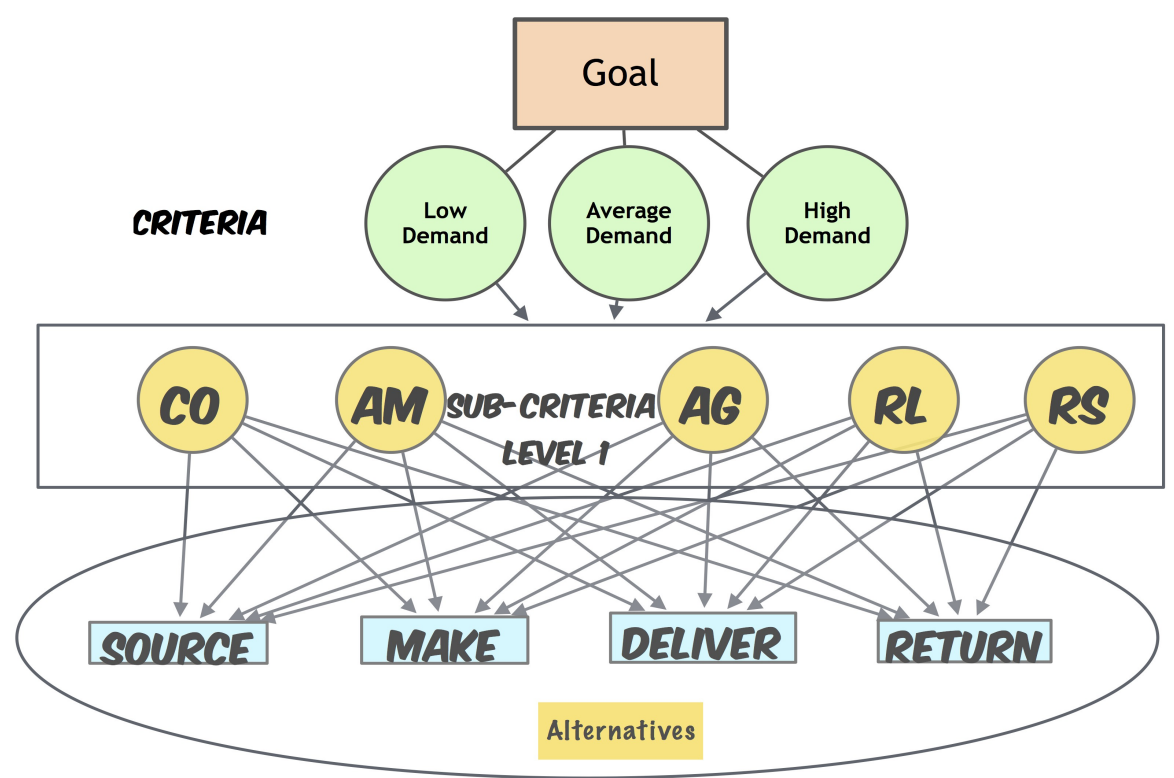

Figure : The supply chain model structure

\begin{tabular}{|c|c|c|}
\hline & Low Demal Average Dı & ema \\
\hline Low Demand & 4.0 & 3.0 \\
\hline Average Demand & & 2.0 \\
\hline High Demand & Incon: 0.10 & \\
\hline
\end{tabular}

Figure : First level judgments using Expert Choice 


\begin{tabular}{l|l|l|l|r|r|r|} 
& Cost & Asst. Mgt & Agility & \multicolumn{2}{|r|}{ Reliability } & Responsiv \\
\hline Cost & & & 3.0 & 4.0 & 1.0 & 4.0 \\
\cline { 2 - 6 } Asst. Mgt & & & 4.0 & 4.0 & 2.0 \\
\hline Agility & & & & 6.0 & 4.0 \\
Reliability & & & & & 4.0 \\
\hline Responsivness & & Incon: 0.07 & & & \\
\hline \hline
\end{tabular}

Figure : Second level judgments sample using Expert Choice.

$$
\begin{aligned}
& \text { Synthesis with respect to: } \\
& \text { Goal: Manage SCP } \\
& \text { Overall Inconsistency = ,08 }
\end{aligned}
$$

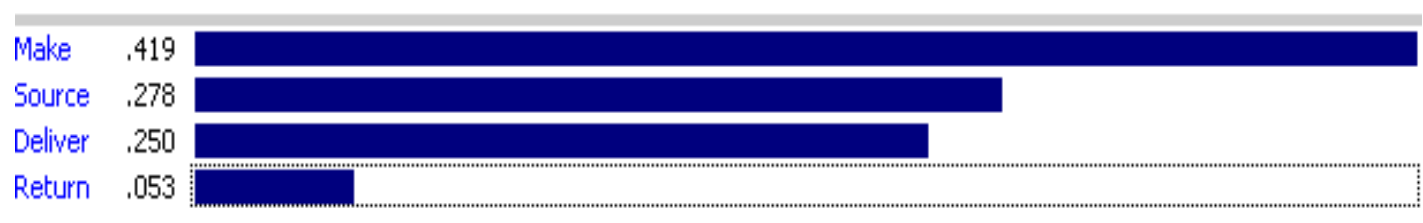

Figure : Overall consistency.

$$
\begin{aligned}
& \square \text { Goal: Manage SCP } \\
& \square \text { Low Demand (L: .124 G: .124) } \\
& \square \text { Cost (L: .334 G: .042) } \\
& \square \text { Asst. Mgt (L: .108 G: .013) } \\
& \square \text { Agility (L: .048 G: .006) } \\
& \square \text { Reliability (L: .373 G: .046) } \\
& \square \text { Responsivness (L: .136 G: .017) } \\
& \square \text { Average Demand (L: .359 G: .359) } \\
& \square \text { Cost (L: .274 G: .098) } \\
& \square \text { Asst. Mgt (L: .081 G: .029) } \\
& \square \text { Agility (L: .081 G: .029) } \\
& \square \text { Reliability (L: .297 G: .107) } \\
& \square \text { Responsivness (L: .267 G: .096) } \\
& \square \text { High Demand (L: .517 G: .517) } \\
& \square \text { Cost (L: .065 G: .034) } \\
& \square \text { Asst. Mgt (L: .054 G: .028) } \\
& \square \text { Agility (L: .094 G: .049) } \\
& \square \text { Reliability (L: .390 G: .202) } \\
& \square \text { Responsivness (L: .397 G: .205) }
\end{aligned}
$$

Figure : Local and global weights of first and second levels. 


\section{Limitations}

The design of the model allows users mainly in SMEs to run, judge, and obtain the most significant supply chain performance attributes and processes based on their preferences, strategy, and product type. However, the model has been implemented in one enterprise only. In addition, we did not examine the effects of each scenario and the selection of attributes and processes associated with them on business profit.

\section{Conclusions}

A quantitative model for supply chain performance improvement with the example used clarifies how practitioners especially in SMEs can implement the model in order to improve business performance. The authors of this paper believe that the outlined model achieves important directions of non-traditional performance measurement system such as: flexibility, easy to use, up to date, comprehensive, involves financial and non-financial measures, and based on business strategy as well. The proposed model also efficiently engages users, mainly in SMEs, to the world of supply chain management and operations. The next step is to run system dynamics simulation program that permits us to examine the impact and effect of the three market scenarios, attributes and processes on business profit.

\section{Key References}

Arend, R. and Wisner, J. (2005). Small business and supply chain management: is there a fit? Journal of business venture, 20 pp. 403-436.

Branch, S. 2012. Key Small Business Statistics - SME Research and Statistics. [online] Available at: http://ic.gc.ca/eic/site/061.nsf/eng/h_02689.html [Accessed: 25 Sep 2013].

Cocca, A. and Alberti, M. 2009. "SME's Three step Pyramid: A new performance measurement framework for SMEs", paper presented at 16th International Annual EUROMA Conference: Implementation-realizing Operations Management Knowledge, Göteborg.

Gosselin, M. 2005. An empirical study of performance measurement in manufacturing firms. International Journal of Productivity and Performance Management, 54 (5/6), pp. 419--437. 